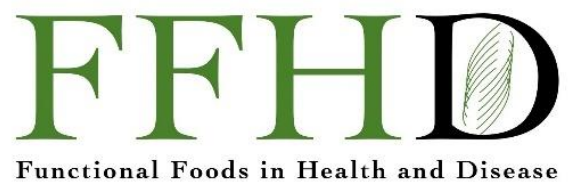

\title{
Hepatoprotective and anti-inflammatory profile of sokeikakketsuto and makyoyokukanto in primary cultured rat hepatocytes
}

Tatsuma Sakaguchi $^{1 *}$, Tetsuya Okuyama ${ }^{1}$, Masaya Kotsuka ${ }^{1}$, Terufumi Yoshida ${ }^{1}$, Tadayoshi Okumura ${ }^{1,2}$, Mikio Nishizawa $^{3}$, Masaki Kaibori ${ }^{1}$ and Mitsugu Sekimoto ${ }^{1}$

\begin{abstract}
${ }^{1}$ Department of Surgery, Kansai Medical University, Hirakata, Japan; ${ }^{2}$ Research Organization of Science and Technology, Ritsumeikan University, Kusatsu, Japan; ${ }^{3}$ Department of Biomedical Sciences, College of Life Sciences, Ritsumeikan University, Kusatsu, Japan
\end{abstract}

*Corresponding Author: Tatsuma Sakaguchi, MD, PhD, Department of Surgery, Kansai Medical University, 2-5-1 Shinmachi, Hirakata, Osaka, 573-1010, Japan

Submission Date: January $4^{\text {th }}, 2022$; Acceptance Date: February $13^{\text {th }}, 2022$; Publication Date: February $15^{\text {th }}, 2022$

Please cite this article as: Sakaguchi T., Okuyama T., Kotsuka M., Yoshida T., Okumura T., Nishizawa M., Kaibori M., Sekimoto M. Hepatoprotective and anti-inflammatory profile of sokeikakketsuto and makyoyokukanto in primary cultured rat hepatocytes. Functional Foods in Health and Disease 2022; 12(2): 81-92. DOI: https://www.doi.org/10.31989/ffhd.v12i2.887

ABSTRACT

Background: Sokeikakketsuto (SOK) is a Kampo medicine that can mitigate several types of pain, including arthralgia, neuralgia, low back pain, and myalgia, which may be introduced for the treatment of neuropathic pain in anti-cancer therapy. Considering that several Kampo medicines are known to have hepatoprotective and anti-inflammatory effects, we investigated the pharmacological mechanism of SOK in hepatocytes. Additionally, we examined another Kampo medicine, makyoyokukanto (MAK), as a reference as it has been reported to have similar efficacy for neuropathic pain.

Methods: SOK or MAK was incubated with rat primary cultured hepatocytes treated with interleukin (IL)-1 $\beta$. The induction of inducible nitric oxide synthase (iNOS), nitric oxide (NO) production, iNOS signaling pathways, and the expression of other inflammatory mediators was investigated. $¥$

Results: IL-1 $\beta$ activated iNOS induction, followed by NO production. SOK and MAK reduced the expression of iNOS mRNA and its protein and decreased NO production. SOK and MAK also decreased the levels of tumor necrosis factor (TNF)- $\alpha$ and increased the levels of IL- 6 and IL-1 $\beta$. Transfection experiments with iNOS promoter-luciferase constructs revealed that MAK reduced iNOS mRNA synthesis and stability; however, SOK only reduced mRNA synthesis. Both medicines suppressed the activation of nuclear factor (NF)-KB but did not block the upregulation of type I IL-1 receptor 
in two essential signaling pathways.

Conclusions: SOK and MAK could prevent NO production by inhibiting iNOS gene expression, partly through NF-KB activation, in inflamed hepatocytes.

Keywords: Kampo medicine, sokeikakketsuto, makyoyokukanto, inducible nitric oxide synthase, cultured hepatocytes

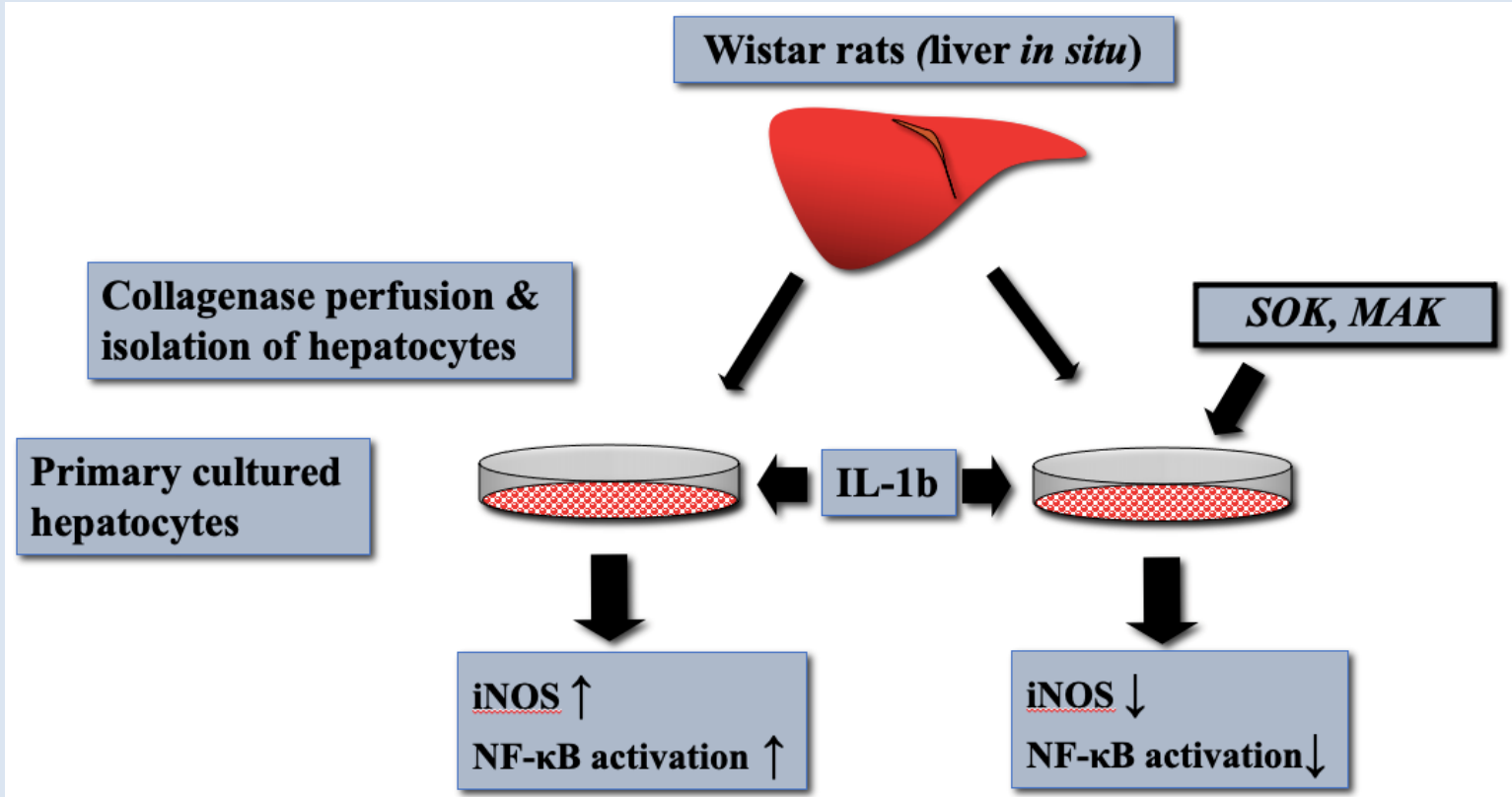

CFFC 2022. This is an Open Access article distributed under the terms of the Creative Commons Attribution 4.0 License (http://creativecommons.org/licenses/by/4.0)

\section{INTRODUCTION}

The Kampo medicine sokeikakketsuto (SOK) is an extract of a mixture of 17 crude drugs (Table 1 ), which has been used in Japanese traditional medicine to relieve pain, including arthralgia, neuralgia, low back pain, and myalgia. The analgesic effect of SOK on chemotherapyinduced peripheral neuropathic symptoms in rats has been demonstrated [1]. Some pharmacological mechanisms of SOK have been elucidated; for example, paeoniflorin from Paeoniae Radix has an inhibitory effect[2]on glutamate release, and isoliquiritigenin from Glycyrrhizae has an N-methyl-D-aspartate (NMDA) antagonist effect[3]. Paeoniflorin[4] and isoliquiritigenin[5] are widely known to have hepatoprotective potential. Furthermore, glycyrrhizin, another component of Glycyrrhizae Radix[6], and a certain fraction of Sojyutu extract[7] have been reported to have hepatoprotective effects. Therefore, SOK may be introduced for the treatment of neuropathic pain with a hepatoprotective profile in anti-cancer therapy.

This study aimed to investigate the hepatoprotective profile of SOK using an in vitro liver injury model, in which primary cultured rat hepatocytes were stimulated by proinflammatory cytokines, leading to nitric oxide (NO) production[8]. Additionally, we examined another Kampo medicine, makyoyokukanto (MAK), as a reference considering that MAK has similar efficacy for alleviating arthralgia, neuralgia, and low back pain but consists of different crude drugs except for Glycyrrhizae Radix (Table 1).

\section{MATERIALS AND METHODS}

Materials: Two types of crude Kampo powder (SOK and MAK; Tsumura, Tokyo, Japan) were dissolved in culture medium $(10 \mathrm{mg} / \mathrm{mL})$ at room temperature for $30 \mathrm{~min}$ with moderate shaking, followed by centrifugation $(10,000 \times g$ for $30 \mathrm{~min})$, filtration $(0.44 \mu \mathrm{m}$ filter), and storage for one month at $4^{\circ} \mathrm{C}$ before use. Recombinant 
human interleukin (IL)-1 $\beta\left(2 \times 10^{7} \mathrm{U} / \mathrm{mg}\right.$ protein) was purchased from MyBioSource (San Diego, CA, USA, catalog\#MBS203125). Male Wistar rats (200-250 g and 6-7 weeks old) were purchased from Charles River (Tokyo, Japan) and kept at $22^{\circ} \mathrm{C}$ under a $12: 12 \mathrm{~h}$ light:dark cycle with ad libitum access to food and water. All experiments on rats were performed in accordance with the Guidelines for the Care and Use of Laboratory Animals of the National Institutes of Health. The experiments were approved by the Animal Care Committee of Kansai Medical University.

In vitro liver injury model: Hepatocytes were isolated from rats by perfusion with collagenase (Wako Pure Chemicals, Kyoto, Japan)[9] suspended in culture medium at $6 \times 10^{5}$ cells $/ \mathrm{mL}$, seeded into $35 \mathrm{~mm}$ plastic dishes ( $2 \mathrm{~mL} /$ dish; Falcon Plastic, Oxnard, CA, USA), and cultured at $37^{\circ} \mathrm{C}$ in a $\mathrm{CO}_{2}$ incubator under a humidified atmosphere with $5 \% \mathrm{CO}_{2}$. The culture medium was Williams' E medium (WE) supplemented with $10 \%$ fetal calf serum, HEPES $(5 \mathrm{mM})$, penicillin $(100 \mathrm{U} / \mathrm{mL})$, streptomycin $(100 \mu \mathrm{g} / \mathrm{mL})$, fungizone $(0.25 \mu \mathrm{g} / \mathrm{mL})$, aprotinin $(0.1 \mu \mathrm{g} / \mathrm{mL}$; Roche, Mannheim, Germany; in the case without serum), $10 \mathrm{nM}$ dexamethasone, and $10 \mathrm{nM}$ insulin. After $2 \mathrm{~h}$, the medium ( $1.5 \mathrm{~mL} /$ dish) was replaced with fresh serum-free and hormone-containing WE (first medium change). After incubation for $5 \mathrm{~h}$, the medium was replaced with fresh serum- and hormone-free WE (second medium change), and the cells were cultured overnight. The number of cells attached to the dishes was determined by counting the number of nuclei[10], and a ratio of $1.37 \pm 0.04$ nuclei/cell was used (mean $\pm S E, n=$ 7 experiments).

Table 1. Crude drugs of the Kampo medicines SOK and MAK

\begin{tabular}{|c|c|}
\hline & SOK (sokeikakketsuto, Tumura53) \\
\hline 1 & Peony Root (Shakuyaku); Paeoniae Radix \\
\hline 2 & Rehmannia Root (Jiou); Rehmanniae Radix \\
\hline 3 & Cnidium Rhizome (Senkyu); Cnidii Rhizoma \\
\hline 4 & Atractylodes Lancea Rhizome (Soujutsu); Atractylodis Lanceae Rhizoma \\
\hline 5 & Japanese Angelica Root (Touki); Angelicae Radix \\
\hline 6 & Peach Kernel (Tounin); Persicae Semen \\
\hline 7 & Poria Sclerotium (Bukuryou); Poria Sclerotium \\
\hline 8 & Clematis Root (Ireisen); Clematidis Radix \\
\hline 9 & Notopterygium (Kyoukatsu); Notopterygii Rhizoma \\
\hline 10 & Achyranthes Root (Goshitsu); Achyranthis Radix \\
\hline 11 & Citrus Unshiu Peel (Chinpi); Aurantii Nobilis Pericarpium \\
\hline 12 & Sinomenium Stem and Rhizome (Boui); Sinomeni Caulis et Rhizoma \\
\hline 13 & Saposhnikovia Root and Rhizome (Boufuu); Glehniae Radix cum Rhizoma \\
\hline 14 & Japanese Gentian (Ryutan); Gentianae Scabrae Radix \\
\hline 15 & Glycyrrhiza (Kanzou); Glycyrrhizae Radix \\
\hline 16 & Angelica Dahurica Root (Byakushi); Angelicae Dahuricae Rhizoma \\
\hline \multirow[t]{2}{*}{17} & Ginger (Shoukyou); Zingiberis Rhizoma \\
\hline & MAK (makyoyokukanto, Tsumura78) \\
\hline 1 & Coicis Semen (Yokuinin) \\
\hline 2 & Armeniacae Semen (Kyounin) \\
\hline 3 & Ephedrae Herba (Maou) \\
\hline 4 & Glycyrrhizae Radix (Kanzou) \\
\hline
\end{tabular}


Treatment of cells with SOK or MAK: On day 1, the cells were washed with fresh serum- and hormone-free WE and incubated with IL-1ß (1 nM) [Nakamura] in the same medium in the presence or absence of SOK or MAK. The doses of SOK or MAK used are indicated in the figures and their legends.

Determination of NO production and lactate dehydrogenase (LDH) activity: The level of nitrite (a stable metabolite of NO) in the culture medium was measured as an indicator of NO production using the Griess method[11]. LDH activity in the culture medium was also measured to reflect cell viability using a commercial kit (Roche Diagnostics, Mannheim, Germany).

Western blot analysis: Total cell lysates were obtained from cultured cells, as described previously[12] with minor modifications. In brief, the cells $\left(1 \times 10^{6}\right.$ cells $/ 35$ $\mathrm{mm}$ dish) were lysed with sample buffer for sodium dodecyl sulfate-polyacrylamide gel electrophoresis (1x SDS-PAGE) (final: 125 mM Tris- $\mathrm{HCl}, \mathrm{pH} 6.8$; containing 5\% glycerol, 2\% SDS, and 1\% 2-mercaptoethanol), subjected to SDS-PAGE, and electroblotted onto a polyvinylidene difluoride membrane (Bio-Rad, Hercules, CA, USA). Immunostaining was performed using primary antibodies against mouse monoclonal inducible nitric oxide synthase (iNOS) (610432; BD Biosciences, Tokyo, Japan), human $\operatorname{IkB} \alpha$ (C21) (sc371; Santa Cruz Biotechnology, Santa Cruz, CA, USA), mouse monoclonal type I IL-1 receptor (IL-1RI) (H-8 sc-393998; Santa Cruz Biotechnology), and rat $\beta$-tubulin (internal control; clone TUB2.1; Sigma Chemical Co., St. Louis, MO, USA). Then, proteins were visualized using an enhanced chemiluminescence detection reagent (GE Healthcare Biosciences Corp., Piscataway, NJ, USA). For Akt, total cell lysates were dissolved in 1×SDS-PAGE sample buffer and analyzed by western blotting using rabbit polyclonal antibodies against human Akt and phospho-Akt (Ser473) (Cell Signaling, Beverly, MA, USA) as primary antibodies.

Reverse transcriptase-polymerase chain reaction (RTPCR): Total RNA was extracted from cultured hepatocytes using the guanidinium-phenol-chloroform method[13] in $1,2,4$ and $6 \mathrm{~h}$. cDNA was synthesized from $1 \mu \mathrm{g}$ of total RNA for each sample with Oligo(dT)20 Primer (25 ng), 5x RT Buffer $(5 \mu \mathrm{L}), 10 \mathrm{mM}$ dNTP mixture $(2.5 \mu \mathrm{L})$, RNase inhibitor (0.5 $\mu \mathrm{L})$, ReverTra Ace (100 $\mathrm{U} / \mu \mathrm{L})$, and UltraPure $^{\mathrm{TM}}$ distilled water (Invitrogen, Carlsbad, CA, USA) (total, $25 \mu \mathrm{L}$ ). The conditions of the thermal cycler (iCycler; Bio-Rad) were as follows: $42^{\circ} \mathrm{C}$ for $60 \mathrm{~min}$ and $95^{\circ} \mathrm{C}$ for $5 \mathrm{~min}$.

The PCR reaction was performed using SYBR Green (Qiagen, Tokyo, Japan) and the primers for each gene. Primer sequences were synthesized by Eurofins Genomics (Tokyo, Japan) and are shown in Table 2. The thermal cycler (Rotor-Gene Q; Qiagen) was programmed as follows: $95^{\circ} \mathrm{C}$ for $5 \mathrm{~min}$, followed by 40 cycles of $95^{\circ} \mathrm{C}$ for $5 \mathrm{~s}$ and $60^{\circ} \mathrm{C}$ for $10 \mathrm{~s}$. Data collection and analysis were performed using the software included in the system. The mRNA level of each gene was measured as the CT value and normalized to that of elongation factor$1 \alpha$ (EF; internal control). The sequence for the rat iNOS was deposited in the DNA Data Bank of Japan (DDBJ)/European Bioinformatics Institute (EMBLEBI)/GenBank under the accession number AB250951.

Table 2. List of primer sets for RT-PCR

\begin{tabular}{|c|c|}
\hline Primer & Nucleotide sequence \\
\hline iNOS F/R & 5'-CCAACCTGCAGGTCTTCGATG-3'/5'-GTCGATGCACAACTGGGTGAAC-3' \\
\hline TNF- $\alpha$ F/R & 5'-TCCCAACAAGGAGGAGAAGTTCC-3'/5'-GGCAGCCTTGTCCCTTGAAGAGA-3' \\
\hline CINC-1 F/R & 5'-GCCAAGCCACAGGGGCGCCCGT-3'/5'-ACTTGGGGACACCCTTTAGCATC-3' \\
\hline HL-1ß F/R & 5'-TCTTTGAAGAAGAGCCCGTCCTC-3'/5'-GGATCCACACTCTCCAGCTGCA-3' \\
\hline IL-6 F/R & 5'-GAGAAAAGAGTTGTGCAATGGCA-3'/5'-TGAGTCTTTTATCTCTTGTTTGAAG-3' \\
\hline EF F/R & 5'-TCTGGTTGGAATGGTGACAACATGC-3'/5'-CCAGGAAGAGCTTCACTCAAAGCTT-3' \\
\hline
\end{tabular}

iNOS, inducible nitric oxide synthase; TNF- $\alpha$, tumor necrosis factor- $\alpha$; CINC-1, cytokine-induced neutrophil chemoattractant-1; IL-1 $\beta$, interleukin-1 $\beta$; IL-6, interleukin-6; EF, elongation factor-1 $\alpha$. F/R, forward/reverse. 
Transfection and luciferase assay: The transfection of cultured hepatocytes was performed as previously described[14-16]. In brief, hepatocytes were cultured at $4 \times 10^{5}$ cells/dish $(35 \times 10 \mathrm{~mm})$ in WE supplemented with serum, dexamethasone, and insulin for $7 \mathrm{~h}$ before magnet-assisted transfection (MATra). The reporter plasmid pRiNOS-Luc-SVpA (iNOS mRNA synthesis) or pRiNOS-Luc-3UTR (iNOS mRNA stabilization) $(1 \mu \mathrm{g})$ and the $\mathrm{CMV}$ promoter-driven $\beta$-galactosidase plasmid pCMV-LacZ (1 ng) as an internal control were mixed with MATra-A reagent ( $1 \mu \mathrm{L}$; IBA GmbH, Göttingen, Germany). After incubation for $15 \mathrm{~min}$ on a magnetic plate at room temperature, the medium was replaced with fresh serum-containing WE. The cells were cultured overnight and treated with IL-1 $\beta$ in the presence or absence of SOK or MAK. The luciferase and $\beta$-galactosidase activities of cell extracts were measured using the PicaGene (Wako Pure Chemicals) and Beta-Glo (Promega, Wisconsin, WI, USA) kits, respectively. The sequence of the iNOS gene promoter was deposited in the DDBJ/EMBL-EBI/GenBank under the accession number AB290142.

\section{Electrophoretic mobility shift assay (EMSA): Nuclear} extracts were prepared, and EMSA was performed as previously described[17]. In brief, nuclear extracts from hepatocytes $(3 \mu \mathrm{g})$ were mixed with $1 \mu \mathrm{g}$ of poly $(\mathrm{dl}-\mathrm{dC})$ and a probe for $20 \mathrm{~min}$ at room temperature (total mixture, $15 \mu \mathrm{L})$. To prepare a double-stranded DNA probe, annealed oligonucleotides harboring a KB site (5'AGTTGAGGGGACTTTCCCAGGC-3'; only the sense strand is shown) were labeled with $\left[\gamma^{-32} \mathrm{P}\right]$-adenosine-5triphosphate (ATP; DuPont-New England Nuclear Japan, Tokyo, Japan) and T4 polynucleotide kinase (Takara Bio Inc., Shiga, Japan). Samples were resolved on a $4.8 \%$ polyacrylamide gel, followed by drying and autoradiography. Protein concentrations were measured with the Bradford[18] method using a binding assay kit (Bio-Rad) with bovine serum albumin as the standard.
Statistical analysis: The results shown are representative of three to four independent experiments with similar findings. All data are expressed as the mean \pm standard deviation (SD). Differences were analyzed by the Bonferroni-Dunn test, and a value of $\mathrm{P}<0.05$ was considered to indicate a significant difference.

\section{RESULTS}

SOK and MAK inhibit the production of $N O$ in hepatocytes: Treatment with the proinflammatory cytokine IL-1 $\beta$ (1 $\mathrm{nM}$ ) increased NO production in primary cultured hepatocytes $[19,20]$. IL-1 $\beta$ increased the level of NO at $4 \mathrm{~h}$ and thereafter (open circles); however, the simultaneous addition of SOK and MAK $(5 \mathrm{mg} / \mathrm{mL})$ inhibited this increase (closed circles) in a timedependent manner (Fig. 1A). SOK and MAK (1-5 mg/mL) also decreased NO production (upper) and iNOS protein induction (middle) in a dose-dependent manner (Fig. 1B). Furthermore, SOK and MAK $(5 \mathrm{mg} / \mathrm{mL})$ inhibited iNOS mRNA expression (Fig. 1C).

SOK and MAK affect inflammatory mediators in hepatocytes: SOK and MAK inhibited tumor necrosis factor (TNF)- $\alpha$ mRNA expression; however, they did not affect the mRNA expression of cytokine-induced neutrophil chemoattractant-1 (CINC-1) and increased IL6 and IL-1 $\beta$ mRNA expression at different levels (Fig. 1D). SOK and MAK showed no cellular cytotoxicity (LDH release in the culture) in hepatocytes (Fig. 2).

MAK but not SOK affects iNOS mRNA synthesis and stability in hepatocytes: SOK and MAK inhibited iNOS induction, as demonstrated previously. Transfection experiments with iNOS promoter-luciferase constructs revealed different mechanisms; MAK inhibited the luciferase activity of both pRiNOS-luc-SVpA (mRNA synthesis) and pRiNOS-Luc-3'UTR (mRNA stability), whereas SOK only inhibited the former (Fig. 3). 
SOK and MAK affect iNOS signaling pathways in hepatocytes: Two signaling pathways are involved in the induction of iNOS in hepatocytes: nuclear factor-kappa B (NF-KB) activation after IKB $\alpha$ degradation and IL-1RI upregulation after the activation (phosphorylation) of Akt (downstream of phosphatidylinositol-3-kinase). SOK and MAK inhibited the activation of NF-KB, which was examined by EMSA; however, both of them did not affect the degradation of IKB $\alpha$ (Fig. $4 \mathrm{~A}$ and $4 \mathrm{~B}$ ). Furthermore,
SOK and MAK did not affect IL-1RI upregulation (Fig. 5A and $5 B)$.

Delayed SOK and MAK treatment inhibits NO production and iNOS induction: The delayed addition of SOK and MAK at 1-3 $\mathrm{h}$ after IL-1 $\beta$ stimulation decreased NO production and iNOS protein induction; however, there were no significant effects thereafter (Fig. 6).
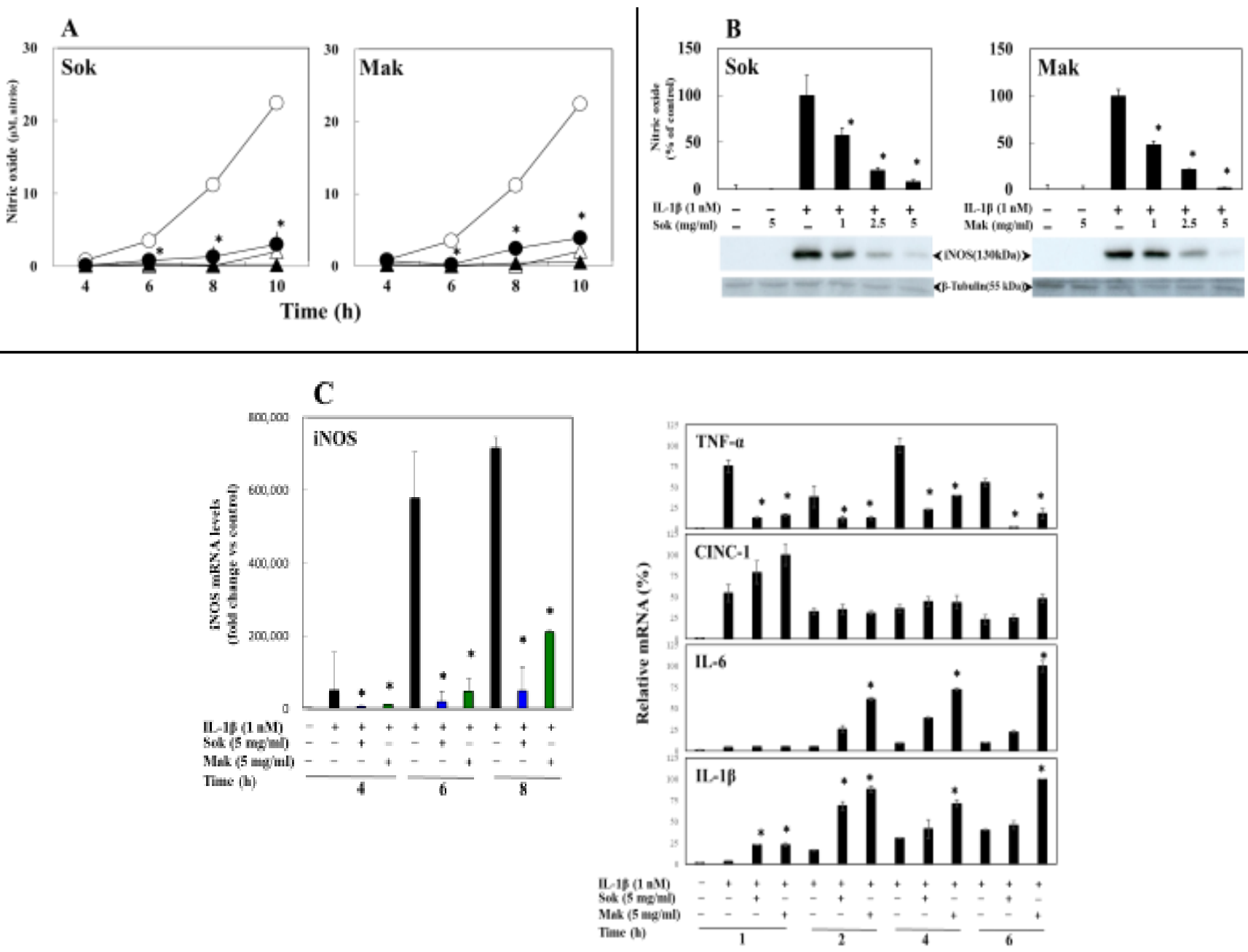

Fig. 1. Effects of SOK and MAK on NO production, iNOS protein expression, and inflammatory mediator (iNOS, TNF- $\alpha$, CINC-1, IL-6, and IL-1 $\beta$ ) mRNA expression in hepatocytes. Cells were treated with interleukin (IL)-1 $\beta$ ( $1 \mathrm{nM}$ ) in the presence or absence of a Kampo medicine (SOK or MAK). (A) Effects of SOK or MAK treatment ( $5 \mathrm{mg} / \mathrm{mL}$ ) for the indicated times on NO production (IL-1 $\beta$, open circles; IL-1 + SOK or MAK, filled circles; SOK or MAK, filled triangles; controls (without IL-1 $\beta$ and SOK or MAK), open triangles). (B) Effects of SOK or MAK treatment at various doses $(1-5 \mathrm{mg} / \mathrm{mL}$ ) for $8 \mathrm{~h}$ on NO production (upper) and iNOS protein expression (middle). Nitrite levels were measured in the culture medium. In the western blot panels, cell lysates (20 $\mu \mathrm{g}$ of protein) were subjected to SDS-PAGE on a $7.5 \%$ gel and immunoblotted with anti-iNOS or anti- $\beta$-tubulin antibody. (C and D) Analysis of total RNA by strand-specific RT-PCR for iNOS, TNF- $\alpha$, CINC-1, IL-6, and IL-1 $\beta$ detection. EF mRNA was used as an internal control. Data are presented as the mean \pm SD for $n=3$ dishes/point. ${ }^{*} \mathrm{P}<0.05$ versus IL- $1 \beta$ alone. 

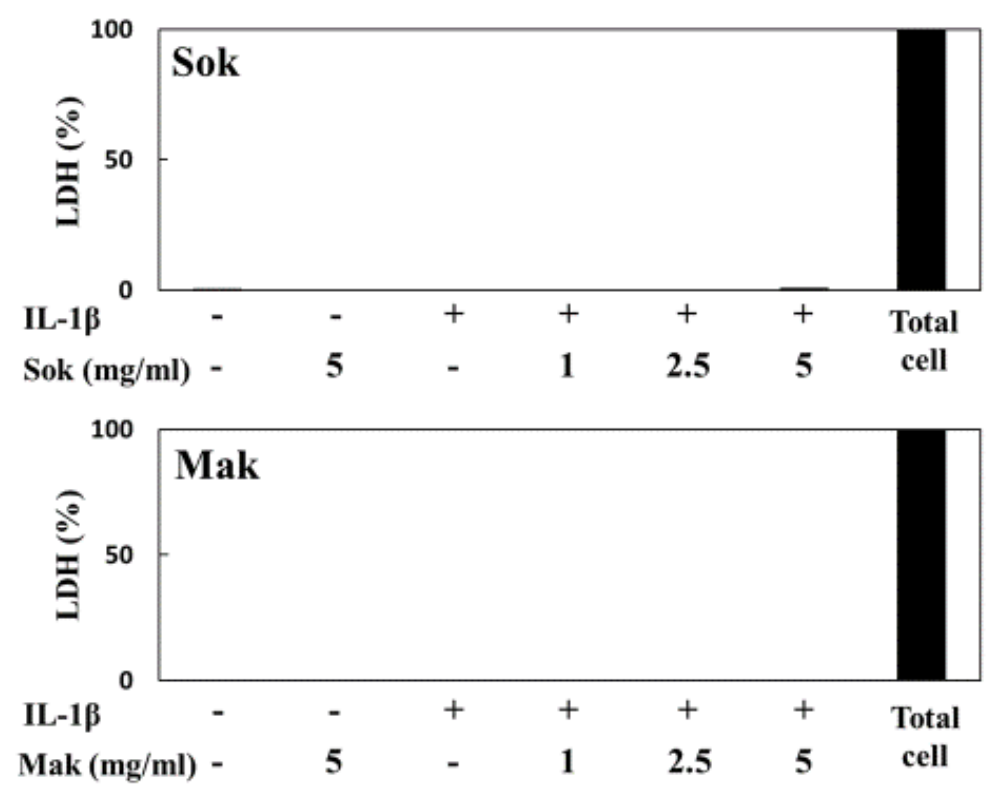

Fig. 2. Effects of SOK and MAK on cellular cytotoxicity. Cells were treated with IL-1 $\beta(1 \mathrm{nM})$ in the presence or absence of SOK or MAK $(1-5 \mathrm{mg} / \mathrm{mL})$ for $8 \mathrm{~h}$. LDH activity was measured in the culture medium. Data are presented as the mean \pm SD $(n=3$ dishes/point).

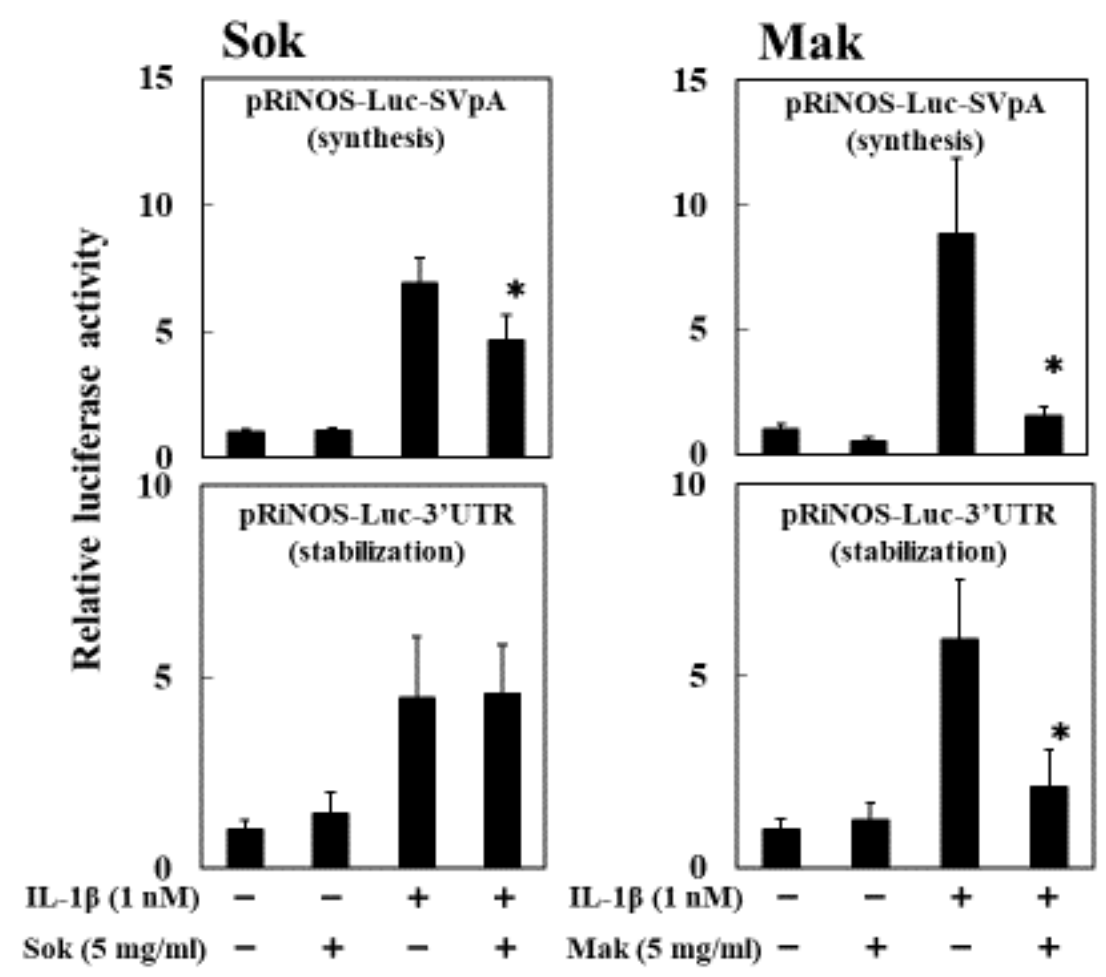

Fig. 3. Effects of SOK and MAK on iNOS promoter transactivation (iNOS mRNA synthesis and stability) in hepatocytes. Two reporter constructs were generated, consisting of the rat iNOS promoter (1.0 kb), a luciferase gene, and the SV40 poly(A) region (pRiNOS-Luc-SVpA) for mRNA synthesis or iNOS 3'-UTR (pRiNOS-Luc-3'UTR) for mRNA stabilization. The iNOS 3'-UTR contains AU-rich elements (AREs) $(A \cup U U(U) A \times 6)$, which contribute to mRNA stabilization. Each construct was introduced into hepatocytes, and the cells were treated with IL-1 $\beta(1 \mathrm{nM})$ in the presence or absence of SOK or MAK $(5 \mathrm{mg} / \mathrm{mL})$ for $7 \mathrm{~h}$ for pRiNOS-Luc-SVpA and $3.5 \mathrm{~h}$ for pRiNOS-Luc-3'UTR. Luciferase activity was normalized to $\beta$-galactosidase activity. Fold activation was calculated by dividing luciferase activity by control activity (without IL-1 $\beta$ and SOK/MAK). Data are presented as the mean \pm SD for $n=3-6$ dishes. *P $<0.05$ versus IL$1 \beta$ alone. 
A

Sok

Mak
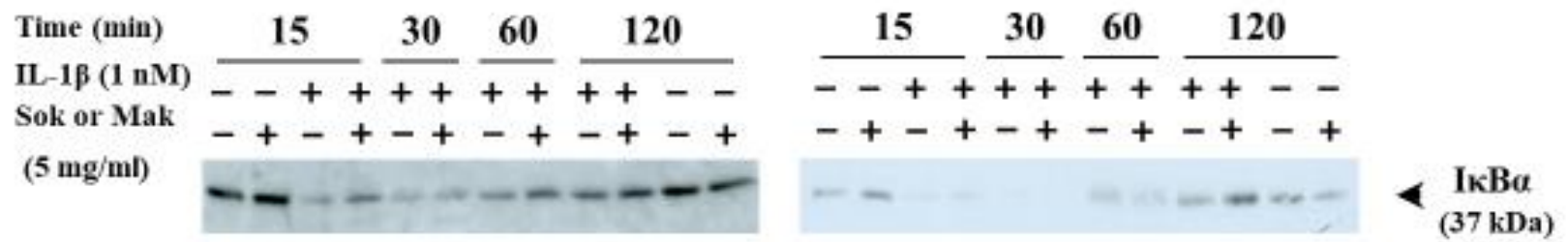

B
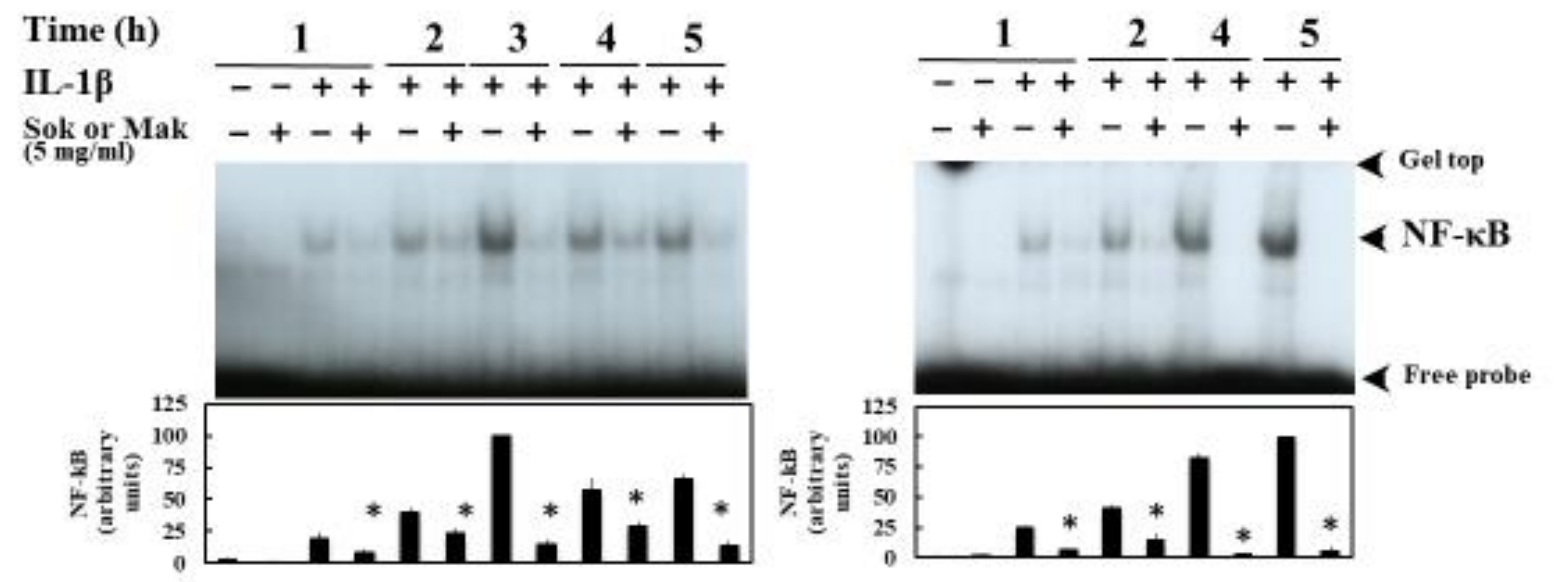

Fig. 4. Effects of SOK and MAK on the degradation of IKB $\alpha$ and activation of NF-KB. Cells were treated with IL-1 (1 nM) in the presence or absence of SOK or MAK $(5 \mathrm{mg} / \mathrm{mL})$ for the indicated times. (A) IKB $\alpha$ degradation. Cell lysates (20 $\mu \mathrm{g}$ of protein) were subjected to SDS-PAGE on a $12.5 \%$ gel, followed by immunoblotting with anti-IKB $\alpha$ antibody. (B) NF-KB activation. Nuclear extracts ( $3 \mu \mathrm{g}$ of protein) were analyzed by EMSA. Representative results of three independent experiments are shown. The bands corresponding to NF-KB were quantified by densitometry (mean \pm SD; $n=3$ experiments). ${ }^{*} \mathrm{P}<0.05$ versus IL- $1 \beta$ alone.

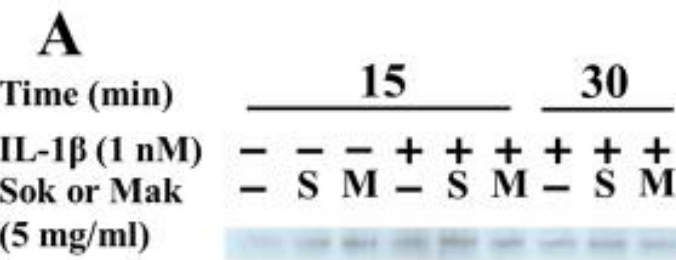

- Phospho-Akt

4 Akt (60 kDa)

\section{B}

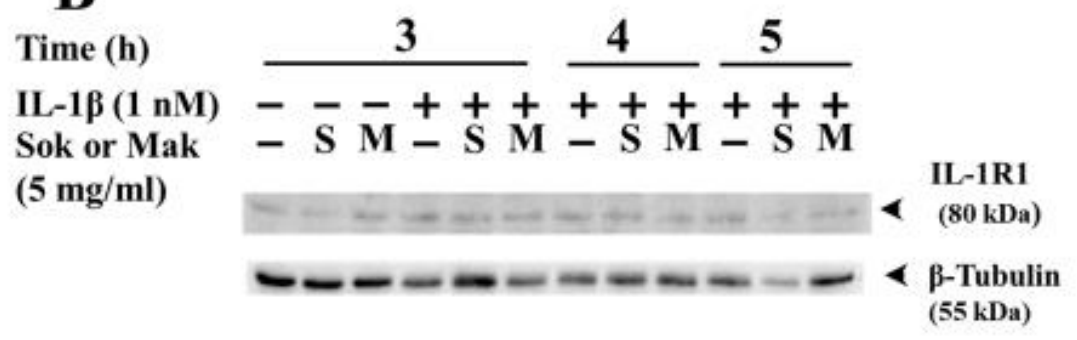

Fig. 5. Effects of SOK and MAK on the upregulation of IL-1RI. Cells were treated with IL-1 $(1 \mathrm{nM})$ in the presence or absence of SOK or MAK $(5 \mathrm{mg} / \mathrm{mL})$ for the indicated times. (A) Phosphorylation of Akt. Total cell lysates were analyzed by SDSPAGE on a $10 \%$ gel, followed by immunoblotting with anti-phospho-Akt (upper) or anti-Akt (lower) antibody. (B) Upregulation of IL1RI. Cell lysates ( $40 \mu \mathrm{g}$ of protein) were subjected to SDS-PAGE on a $7.5 \%$ gel and immunoblotted with anti-IL-1RI or anti- $\beta$-tubulin antibody. 


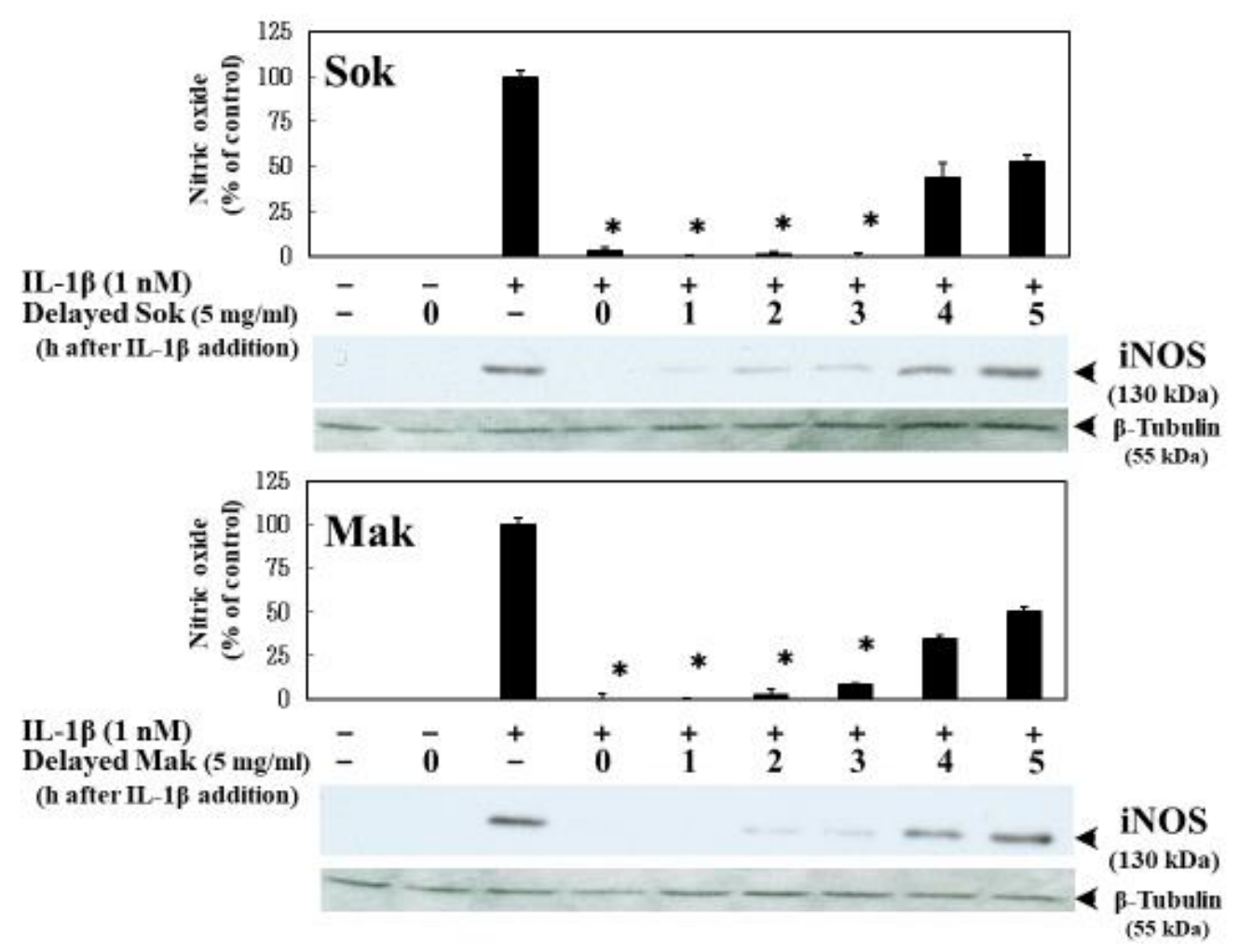

Fig. 6. Effects of delayed SOK and MAK administration on iNOS induction in hepatocytes. Cells were treated with SOK or MAK $(5 \mathrm{mg} / \mathrm{mL})$ at $0-4 \mathrm{~h}$ after the addition of IL-1 $\beta(1 \mathrm{nM})$. The effects of SOK/MAK on NO production (upper panel) and iNOS protein (middle panel) were analyzed at $8 \mathrm{~h}$ after the addition of IL-1 $\beta$. Nitrite levels were measured in the culture medium. Data are presented as the mean $\pm S D$ ( $n=3$ dishes/point); ${ }^{*} P<0.05$ versus IL-1 $\beta$ alone. In the western blot panels, cell lysates (20 $\mu \mathrm{g}$ of protein) were subjected to SDS-PAGE on a $7.5 \%$ gel and immunoblotted with anti-iNOS or anti- $\beta$-tubulin antibody.

\section{DISCUSSION}

In the current study, SOK and MAK inhibited iNOS induction and NO production in IL-1 $\beta$-stimulated hepatocytes by suppressing NF-KB activation. Both medicines also inhibited TNF- $\alpha$ mRNA expression. These results suggest that SOK and MAK may have hepatoprotective and anti-inflammatory effects. SOK may be used in anti-cancer therapy for patients with neuropathic pain ${ }^{1}$. Patients with advanced cancers tend to have cachexia, which is associated with inflammatory changes[21]. The anti-inflammatory effects of SOK have the potential to mitigate cancer-related refractory syndromes. In addition, the hepatoprotective profile of SOK is better compared with that of other analgesics. Although acetaminophen is one of the most frequently used drugs due to its analgesic and antipyretic properties, an overdose of acetaminophen is a major cause of acute liver failure[22]. Duloxetine, which is the only recommended drug for neuropathy treatment in the American Society of Clinical Oncology (ASCO) Guideline 2020, also has the potential to cause drug-induced liver injury[23]. On the other hand, SOK has minimal adverse effects;[1] thus, it would be beneficial if the administration of SOK could reduce the excessive use of these analgesics. Interestingly, MAK demonstrated a mechanism similar to that of SOK by inhibiting NO production in hepatocytes; however, these two Kampo medicines are composed of different crude drugs except for Glycyrrhizae Radix. Nakamura et al. reported that the maximum effect was achieved at $30 \mathrm{~min}$ after the administration of SOK[1]. We also demonstrated that the delayed addition of SOK and MAK at 1-3 $h$ after treatment with IL-1 $\beta$ decreased NO production and iNOS protein induction. These results suggest that SOK and MAK may be administered for pain management in both routine and rescue situations. 
NO is produced from L-arginine by three isoforms of NOS: neuronal NOS (nNOS), endothelial NOS (eNOS), and iNOS. NO plays important roles in various pathophysiological processes. The production of NO by iNOS and inflammatory cytokines such as TNF- $\alpha$ and IL$1 \beta$ has been implicated as a factor in liver injury[24-26]. We previously reported that IL-1 $\beta$ stimulated the expression of iNOS and CXCL1 (human IL-8 analog) in primary rat hepatocyte cultures, which led to excess NO production (in vitro liver injury model)[8]. In the induction of iNOS, there are two essential signaling pathways, the IKB degradation/NF-KB activation through IKB kinase and IL-1RI upregulation through phosphatidylinositol 3-kinase (PI3K)/Akt [27]. SOK and MAK had no effects on the both signaling pathways, but reduced NF-KB activation, its nuclear translocation from cytoplasm and DNA binding. The elevation of mRNA of IL$1 \beta$ and IL-6, both of which were the target genes of NFKB [28], were inhibited in hepatocytes by the treatment of SOK and MAK. The hepatoprotective effects of clinical drugs, traditional medicines, and functional foods may be determined using an in vitro liver injury model; the prevention of iNOS induction and NO production, as well as the inhibition of TNF- $\alpha$ expression, may indicate liver protection. In neurotransmission including pain perception in the spinal cord, activation of the NMDA subtype of glutamate receptors and subsequent NO production are key events[29]. NO produced by nNOS, but not eNOS or iNOS, in the spinal cord is mainly involved in the maintenance of neuropathic pain. However, it has been shown that NO itself can enhance nNOS activity mediated by NMDA receptors[30].

Limitation of this study is that this is an in vitro study using hepatocytes indicated that the inhibition of NO production is a key pharmacological mechanism of SOK and MAK. Further investigation is warranted in the context of cultured neurons, in vivo models of neuropathic pain, and clinical trials.

\section{CONCLUSION}

In conclusion, two different Kampo medicines (SOK and MAK) with similar efficacy for neuropathic pain had hepatoprotective and anti-inflammatory effects on proinflammatory-stimulated primary cultured rat hepatocytes.

Abbreviations: SOK: sokeikakketsuto, MAK: makyoyokukanto, iNOS: inducible nitric oxide synthase,

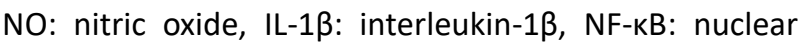
factor-kappa B, IL-1RI: type I interleukin-1 receptor, TNF$\alpha$ : tumor necrosis factor-alpha, CINC-1: cytokine-induced neutrophil chemoattractant-1

Disclosure of potential conflicts of interest: The authors declare that they have no conflicts of interest.

Authors' contributions: TS and TeO participated in data collection, statistical analysis, and drafting the manuscript. MaK and TY assisted in data collection, and MK provided advice on the development of the protocol for the study. MN, TO, and MS assisted in the design of the study, supervised the study, and provided oversight when the manuscript was being drafted.

Funding and Acknowledgments: This study was supported in part by a Grant-in-Aid for Scientific Research from the Ministry of Education, Science, Culture, and Sports of Japan and by grants from the Science Research Promotion Fund of the Japan Private School Promotion Foundation.

\section{REFERENCES}

1. Nakamura H, Kawashiri T, Kobayashi D, Uchida M, Egashira N, Shimazoe T. Analgesic Effects of Sokeikakketsuto on Chemotherapy-Induced Mechanical Allodynia and Cold Hyperalgesia in Rats. Biological and Pharmaceutical Bulletin. 2021;44(2):271-274. doi:10.1248/bpb.b20-00620

2. Zhang XJ, Chen HL, Li Z, et al. Analgesic effect of paeoniflorin in rats with neonatal maternal separation-induced visceral hyperalgesia is mediated through adenosine $\mathrm{A} 1$ receptor by inhibiting the extracellular signal-regulated protein kinase 
(ERK) pathway. Pharmacology Biochemistry and Behavior. 2009;94(1):88-97. doi:10.1016/j.pbb.2009.07.013

3. Kawakami Z, Ikarashi Y, Kase Y. Isoliquiritigenin is a Novel NMDA Receptor Antagonist in Kampo Medicine Yokukansan. Cellular and Molecular Neurobiology. 2011;31(8):1203-1212. doi:10.1007/s10571-011-9722-1

4. Kim ID, Ha BJ. The effects of paeoniflorin on LPS-induced liver inflammatory reactions. Archives of Pharmacal Research. 2010;33(6):959-966. doi:10.1007/s12272-010-0620-8

5. Chen $X$, Cai $X$, Le $R$, et al. Isoliquiritigenin protects against sepsis-induced lung and liver injury by reducing inflammatory responses. Biochemical and Biophysical Research Communications. 2018;496(2):245-252. doi:10.1016/j.bbrc.2017.11.159

6. Kwon YJ, Son DH, Chung TH, Lee YJ. A Review of the Pharmacological Efficacy and Safety of Licorice Root from Corroborative Clinical Trial Findings. Journal of Medicinal Food. 2020;23(1):12-20. doi:10.1089/imf.2019.4459

7. Ishii T, Okuyama T, Noguchi $\mathrm{N}$, et al. Correction to: Antiinflammatory constituents of Atractylodes chinensis rhizome improve glomerular lesions in immunoglobulin $\mathrm{A}$ nephropathy model mice. Journal of Natural Medicines. 2020;74(3):616-616. doi:10.1007/s11418-020-01405-w

8. Kaibori M, Okumura T, Sato K, Nishizawa M, Kon M. Inducible Nitric Oxide Synthase Expression in Liver Injury: Liver Protective Effects on Primary Rat Hepatocytes. Inflammation and Allergy-Drug Targets. 2016;14(2):77-83. doi:10.2174/1871528114666160330113227

9. Seglen PO. Chapter 4 Preparation of Isolated Rat Liver Cells. In: 1976:29-83. doi:10.1016/S0091-679X(08)61797-5

10. Horiuti Y, Ogishima M, Yano K, Shibuya Y. Quantification of cell nuclei isolated from hepatocytes by cell lysis with nonionic detergent in citric acid. Cell structure and function. 1991;16(3):203-207. doi:10.1247/csf.16.203

11. Green LC, Wagner DA, Glogowski J, Skipper PL, Wishnok JS, Tannenbaum SR. Analysis of nitrate, nitrite, and [15N]nitrate in biological fluids. Analytical Biochemistry. 1982;126(1):131138. doi:10.1016/0003-2697(82)90118-X

12. Nakanishi H, Kaibori M, Teshima S, et al. Pirfenidone inhibits the induction of iNOS stimulated by interleukin-1 $\beta$ at a step of NF-KB DNA binding in hepatocytes. Journal of Hepatology. 2004;41(5):730-736. doi:10.1016/j.jhep.2004.07.007

13. CHOMZYNSKI P. Single-Step Method of RNA Isolation by Acid Guanidinium Thiocyanate-Phenol-Chloroform Extraction. Analytical Biochemistry. 1987;162(1):156-159. doi:10.1006/abio.1987.9999

14. Nishizawa M. Regulation of inducible gene expression by natural antisense transcripts. Frontiers in Bioscience. 2012;17(1):938. doi:10.2741/3965

15. Matsui K, Nishizawa M, Ozaki T, et al. Natural antisense transcript stabilizes inducible nitric oxide synthase messenger RNA in rat hepatocytes. Hepatology. 2007;47(2):686-697. doi:10.1002/hep.22036

16. Matsui K, Kawaguchi Y, Ozaki T, et al. Effect of Active Hexose Correlated Compound on the Production of Nitric Oxide in Hepatocytes. Journal of Parenteral and Enteral Nutrition. 2007;31(5):373-381. doi:10.1177/0148607107031005373

17. Oda M, Sakitani K, Kaibori M, Inoue T, Kamiyama Y, Okumura T. Vicinal Dithiol-binding Agent, Phenylarsine Oxide, Inhibits Inducible Nitric-oxide Synthase Gene Expression at a Step of Nuclear Factor-KB DNA Binding in Hepatocytes. Journal of Biological Chemistry. 2000;275(6):4369-4373. doi:10.1074/jbc.275.6.4369

18. Bradford M. A Rapid and Sensitive Method for the Quantitation of Microgram Quantities of Protein Utilizing the Principle of Protein-Dye Binding. Analytical Biochemistry. 1976;72(1-2):248-254. doi:10.1006/abio.1976.9999

19. Kitade $\mathrm{H}$. Interleukin 1 beta markedly stimulates nitric oxide formation in the absence of other cytokines or lipopolysaccharide in primary cultured rat hepatocytes but not in Kupffer cells. Hepatology. 1996;23(4):797-802. doi:10.1053/jhep.1996.v23.pm0008666334

20. Kleinert H, Pautz A, Linker K, Schwarz PM. Regulation of the expression of inducible nitric oxide synthase. European Journal of Pharmacology. 2004;500(1-3). doi:10.1016/i.ejphar.2004.07.030

21. Seelaender M, Laviano A, Busquets $S$, Püschel GP, Margaria T, Batista ML. Inflammation in Cachexia. Mediators of Inflammation. 2015;2015:1-2. doi:10.1155/2015/536954

22. Chun LJ, Tong MJ, Busuttil RW, Hiatt JR. Acetaminophen Hepatotoxicity and Acute Liver Failure. Journal of Clinical Gastroenterology. 2009;43(4):342-349. doi:10.1097/MCG.0b013e31818a3854

23. Voican CS, Corruble E, Naveau S, Perlemuter G. Antidepressant-Induced Liver Injury: A Review for Clinicians. American Journal of Psychiatry. 2014;171(4):404-415. doi:10.1176/appi.ajp.2013.13050709

24. Sakaguchi T, Hashimoto $Y$, Matsushima H, et al. Levosimendan pretreatment improves survival of septic rats after partial hepatectomy and suppresses iNOS induction in cytokinestimulated hepatocytes. Scientific Reports. 2019;9(1):13398. doi:10.1038/s41598-019-48792-z

25. Iwakiri Y, Kim MY. Nitric oxide in liver diseases. Trends in Pharmacological Sciences. 2015;36(8):524-536. $\underline{\text { doi:10.1016/j.tips.2015.05.001 }}$ 
26. Colasanti $M$, Suzuki $H$. The dual personality of NO. Trends in Pharmacological Sciences. 2000;21(7):249-252.

doi:10.1016/S0165-6147(00)01499-1

27. Teshima S, Nakanishi $H$, Nishizawa $M$, et al. Up-regulation of IL-1 receptor through PI3K/Akt is essential for the induction of iNOS gene expression in hepatocytes. Journal of Hepatology. 2004;40(4):616-623.

doi:10.1016/i.jhep.2003.12.018

28. Pahl HL. Activators and target genes of Rel/NF-KB transcription factors. Oncogene. 1999;18(49):6853-6866. doi:10.1038/sj.onc.1203239

29. Meller ST, Gebhart GF. Nitric oxide (NO) and nociceptive processing in the spinal cord. Pain. 1993;52(2):127-136. doi:10.1016/0304-3959(93)90124-8

30. Xu L, Mabuchi T, Katano T, et al. Nitric oxide (NO) serves as a retrograde messenger to activate neuronal NO synthase in the spinal cord via NMDA receptors. Nitric Oxide. 2007;17(1):18-24. doi:10.1016/i.niox.2007.04.004 